\title{
Fracture Behavior of Rock with Initial Damage: Theoretical, Experimental, and Numerical Investigations
}

\author{
Hui Zhang, ${ }^{1}$ Panpan Guo $\mathbb{D}^{2},{ }^{2}$ Yixian Wang $\mathbb{D}^{1},{ }^{1}$ Yanlin Zhao $\mathbb{D}^{3}$ Hang Lin, ${ }^{4}$ Yan Liu, ${ }^{5}$ \\ and Yahui Shao ${ }^{1}$ \\ ${ }^{1}$ School of Civil Engineering, Hefei University of Technology, Hefei 230009, China \\ ${ }^{2}$ Research Center of Coastal and Urban Geotechnical Engineering, Zhejiang University, Hangzhou 310058, China \\ ${ }^{3}$ School of Energy and Safety Engineering, Hunan University of Science and Technology, Xiangtan 411201, China \\ ${ }^{4}$ School of Resources and Safety Engineering, Central South University, Changsha 410083, China \\ ${ }^{5}$ State Key Laboratory of Explosion Science and Technology, Beijing Institute of Technology, Beijing 100081, China
}

Correspondence should be addressed to Panpan Guo; pp_guo@zju.edu.cn and Yixian Wang; wangyixian2012@hfut.edu.cn

Received 19 May 2020; Revised 24 June 2020; Accepted 5 September 2020; Published 22 September 2020

Academic Editor: Jinze Xu

Copyright (c) 2020 Hui Zhang et al. This is an open access article distributed under the Creative Commons Attribution License, which permits unrestricted use, distribution, and reproduction in any medium, provided the original work is properly cited.

\begin{abstract}
Geomaterials such as rock mass often have initial damage under the influence of long-term geological action and hydration corrosion environment. The initial damage affects the integrity and stability of the rock mass, resulting in a difference in the mechanical properties of jointed rock mass and intact one. Therefore, the study of the fracture and failure characteristics of the jointed rock mass is of great significance. Most of the previous researches into the fracture behavior of rock with initial damage are based on model testing, theoretical analysis, and numerical simulation of rock mass with preexisting flaws. This review concentrates on the theoretical, experimental, and numerical efforts that have been devoted to the fracture characteristics of rock or rock-like specimens with preexisting flaws under compression. Some suggestions on the future research work in this field are also given.
\end{abstract}

\section{Introduction}

In practical engineering structures, natural rock masses often have initial damage such as joints and fissures under the influence of long-term geological action and hydration corrosion environment. These defects affect the integrity of the rock, resulting in nonlinear, heterogeneous, anisotropy, and other characteristics of the rock mass $[1,2]$. The mechanical properties of fissured rock mass are significantly different from that of intact rock. Under the action of crustal stress and external load, stress concentration will appear in defects of rock mass, leading to the initiation, extension, and coalescence of new cracks and finally the destruction of the rock mass [3-7]. Therefore, the study of the fracture and failure characteristics of jointed rock mass is of great significance to engineering.
Most researches on the fracture and mechanism characteristics of jointed rock mass are based on the study of the rock model with preexisting flaws [8-13]. And the present researches mainly focus on the exploration of crack initiation criteria, small model experiment, and numerical simulation. Plenty of scholars have devoted their efforts to this research area and have achieved fruitful results [14-17]. However, with the continuous accumulation of research results in this area, in order to avoid repeated work or meaningless work, it is necessary to analyze and summarize these research results. An effective summary can extract general laws from existing research and use them to guide practice. On the other hand, it can also find vacancies and deficiencies from the existing research, so as to point out the direction for the follow-up research of scholars. 
Considering that there are few summary works on the fracture behavior of rock with initial damage at present, this review briefly concludes these achievements in theoretical, experimental, and numerical aspects aiming to keep readers informed of the research progress in this field and give them suggestions on the problems and the future research direction.

\section{Theoretical Achievements on Fracture Criteria}

Fracture criteria and crack initiation mechanism of flaws under compression are essential problems in rock fracture mechanics. Inclined preexisting flaws in rock models are often under the compression and shear stress condition, and the fracture in these rock models under compression is often a kind of mixed-mode fracture. At present, the most basic and commonly used mixed-mode fracture criteria are the maximum tangential stress criterion [18, 19], maximum energy release rate criterion [20-22], and minimum strain energy density factor criterion [23]. Many other criteria are developed based on them [24].

The maximum tangential stress criterion theory is the most widely used criterion which can be described as the following: (1) crack initiates along the direction of maximum tangential stress, and (2) when the maximum tangential stress at the flaw tip reaches a critical value, the crack initiates. The corresponding formula is as follows:

$$
\begin{gathered}
\left.\frac{\partial \sigma_{\theta \theta}}{\partial \theta}\right|_{\theta=\theta_{0}}=0, \\
\left.\frac{\partial^{2} \sigma_{\theta \theta}}{\partial \theta^{2}}\right|_{\theta=\theta_{0}}<0, \\
\left.\sigma_{\theta \theta}\right|_{\theta=\theta_{0}}=\sigma_{c},
\end{gathered}
$$

where $\sigma_{\theta \theta}$ is the tangential stress at the flaw tip and $\sigma_{c}$ is the critical value of the tangential stress. The analysis results can well reflect the differences of fracture types of cracks under the action of tension and compression, and the results obtained are in good agreement with the experimental results, which makes it widely used in the theoretical research and practical engineering of rock failure [25-28].

Sih [23] proposed the minimum strain energy density factor criterion and described that the crack initiates along the direction of the minimum strain energy density factor when it reaches a critical value:

$$
\begin{gathered}
\left.\frac{\partial S}{\partial \theta}\right|_{\theta=\theta_{0}}=0, \\
\left.\frac{\partial^{2} S}{\partial \theta^{2}}\right|_{\theta=\theta_{0}}>0, \\
\left.S\right|_{\theta=\theta_{0}}=S_{c},
\end{gathered}
$$

where $S$ is the strain energy density factor and $S_{c}$ is the critical value of the strain energy density factor. The application of this theory is convenient, and the two-dimensional model is in good agreement with the experimental results [29-31]. However, there are many controversies for the reason that the connection between this theory and the physical nature of material destruction is not clear.

The maximum energy release rate criterion is another energy-based criterion that is widely applied [32, 33]. It proposed that a crack initiates when the maximum energy release rate reaches a critical value which can be accepted readily at the physical level:

$$
\begin{gathered}
\left.\frac{\partial G_{\theta}}{\partial \theta}\right|_{\theta=\theta_{0}}=0, \\
\left.\frac{\partial^{2} G_{\theta}}{\partial \theta^{2}}\right|_{\theta=\theta_{0}}<0, \\
\left.G\right|_{\theta=\theta_{0}}=G_{c},
\end{gathered}
$$

where $G$ is the energy release rate and $G_{c}$ is the critical value of the energy release rate. However, the value of the energy release rate $G$ is not easy to obtain when a crack initiates not along the direction of the original flaw, and it is difficult to explain the fracture path observed by experiments.

With the development of rock fracture mechanics, there are many other theories which have been proposed based on the above classical criteria. Matvienko [34] proposed the maximum mean tangential stress (mean tensile stress along the line in front of the incision) theory, which suggested that the crack growth of rock-like materials always extends along the direction of the maximum mean circumferential stress in the area near the flaw. Khan and Khraisheh [35] proposed a modified maximum tangential stress criterion based on maximum tangential stress, taking into account the elasticplastic boundary of the flaw tip. Shen $[36,37]$ proposed a modification of the $G$-criterion for crack propagation subjected to compression named " $F$-criteria."

These classical and modified criteria are mostly based on mode I fracture (tension fracture) and seldom consider the mode II fracture of compression-shear flaws. As the mode II fracture is nonignorable, many scholars have proposed their theories to predict this mode of fracture [38-40]. Sun $[38,39]$ analyzed the stress field of the flaw tip under pure shear, developed the criterion of maximum tangential tensile stress, and made it possible to judge the type of shear fracture. Based on the energy release rate criterion, Chang et al. [40] developed a more general composite fracture criterion, which could be used for I-II composite fracture problems, and most of the fracture criteria could be degraded by it.

However, until now, many fracture mechanics theories remain controversial, and there is a lack of a commonly applicable or generally accepted theory. Moreover, theoretical studies on rock fracture mainly focus on $2 \mathrm{D}$ crack propagation, and there are few studies on three-dimensional crack because of the complexity of this situation. Therefore, the theoretical research on rock fracture in the future should 
focus on exploring a more reasonable two-dimensional fracture theory and strengthening the research on threedimensional crack growth.

\section{Experimental Specimens and Results}

Experimental research is a primary way to explore the failure mode and fracture mechanism of rock for its function in reflecting the actual situation of rock fracture progress more directly and veritably. In the past decades, scholars have applied many kinds of specimens that vary in materials, numbers, and types of preexisting two-dimensional flaws as shown in Table 1.

Undoubtedly, natural rocks are ideal materials for the experiment and should be the first choice for researchers $[41,42,44-47,49,63,64]$. The most widely used rock materials are granite, sandstone, and marble. In addition, rocklike materials, such as cement mortar, gypsum, glass, and PMMA (polymethylmethacrylate), can also be applied to make specimens to simulate rocks for the reason that they have similar mechanical properties with rock and are easy to produce [50, 51, 54, 56-58].

Many scholars have employed the specimens containing different numbers of preexisting flaws to investigate the fracture characteristics of rock mass with different numbers of joints. Single-flaw specimens are often used to investigate crack initiation and propagation $[3,8,10,59]$, while multiflaw specimens are mainly employed to study the interaction of preexisting flaws and the coalescence after crack initiation and propagation $[12,55,60]$. A large number of experimental studies indicated that the crack initiation from the $2 \mathrm{D}$ preexisting flaws could be generally classified into two types $[9,39,64]$ : wing (or primary) cracks and secondary cracks as shown in Figure 1. Wing cracks appear first, which are the tensile cracks that initiate from the tips of the flaw and propagate in a stable manner towards the direction of maximum compression. Secondary cracks are generally described as shear cracks or shear zones. Secondary cracks initiate from the tips of the flaw, and two directions are possible: (1) coplanar or quasicoplanar to the flaw and (2) with an inclination similar to the wing cracks but in the opposite direction (antiwing crack).

Apart from a single flaw, specimens containing two or more flaws were always employed to investigate the coalescence pattern of the cracks. Shen et al. [65] observed that the coalescence modes of the cracks are determined by the fracture-bridge inclination and indicated 5 types of coalescence. Bobet and Einstein [48] carried out uniaxial and biaxial compression tests on gypsum specimens with preexisting flaws and identified five different types of coalescence with a combination of tensile and shearing processes. Park and Bobet [60] found that in specimens with more than two flaws, coalescence could be produced by the linkage through wing cracks, secondary cracks, or their combination. Figure S1 presents some experimental results of rock specimens containing more than one flaw. It can be seen clearly that the preexisting flaws in the specimen are interrelated, and different numbers and locations of flaws will lead to different types of crack coalescence.
Due to the limitation of test conditions, most of the experimental studies mentioned above are about the initiation and propagation of two-dimensional flaws. However, most of the flaws in the actual rock mass are threedimensional flaws, which are usually in the inner part of the rock mass. Moreover, most of the simulated materials used by scholars are opaque materials, making it difficult to directly observe the initiation and propagation process of rock fractures and understand the propagation state of cracks in the rock mass under different stress states in real time. Therefore, the researches of three-dimensional flaws have made slow progress in a long period of time. In the 1990s, Dyskin et al. [66-68] used resin materials to make specimens with three-dimensional surface flaws. Uniaxial and triaxial compression tests were then carried out on these specimens after treatment at low temperature. The experimental results show that the growth of the wing crack stops when it grows to a certain extent because the enveloped wing crack is generated at the edge of the prefabricated flaw. That is completely different from 2D situations. In 2004, Wong et al. [58] employed marble and PMMA specimens containing threedimensional surface flaws to study the expansion mechanism of this kind of flaw. During the test, it was found that not only a wing crack but also a petal-shaped crack (Figure S2) which has not appeared in 2D situations appeared in the tip area of the flaw. This study shows that the propagation process of a surface crack is influenced by the material properties, specimen thickness, flaw depth, and flaw inclination. In 2016, Zhu et al. [69] developed a kind of transparent rocklike material with similar properties to rock to observe and study the propagation and connection mechanism of the internal three-dimensional flaw. The experimental results show that the secondary cracks have different propagation and transfixion modes under different bridge angles and flaw spacing. The secondary cracks observed in the test included wing cracks, antiwing cracks, and petal-like cracks under the action of tension and shear.

No matter in two-dimensional or three-dimensional cases, the numerous above-mentioned experimental results show that the initial damage in rock has a huge impact on its mechanical properties and cracking process, which is reflected in the following: (1) The strength of rock with initial damage is far less than that of intact rock. (2) The initial damage is the inducement of crack initiation. Under the action of load, almost all of the cracks initiate from the preexisting flaws. And (3) the number, location, and type of the initial flaws will determine the initiation, propagation, and coalescence of cracks that are induced by external stress, resulting in different failure modes of specimens.

Almost all of the experimental study on threedimensional flaws found that there are many differences between three-dimensional flaws and two-dimensional flaws in rock mass, which indicates that an experimental test of three-dimensional flaws is extremely necessary for the study of actual rock mass flaws. In addition, most of the present three-dimensional experiments focus on three-dimensional surface flaws using completely homogeneous transparent materials. Considering that most flaws in the rock mass are located in the inside of the rock mass and the rock material 
TABLE 1: Different kinds of specimens for rock fracture test.

\begin{tabular}{|c|c|c|c|}
\hline Materials & & Flaw type & Flaw number \\
\hline \multirow{4}{*}{ Natural rocks } & Granite & Open & $1[3,8,41], 2[8,12,42], 3[43]$ \\
\hline & \multirow{2}{*}{ Sandstone } & Closed & $2[44]$ \\
\hline & & Open & $1[3], 2[45], 3[46]$ \\
\hline & Marble & Open & $1[13,47,48], 2[49]$ \\
\hline \multirow{6}{*}{ Rock-like materials } & \multirow{2}{*}{ Cement mortar } & Closed & Multiple $[50,51]$ \\
\hline & & Open & $1[52,53], 2[11,54,55], 3[11]$, multiple $[56,57]$ \\
\hline & \multirow{2}{*}{ PMMA } & Closed & $1[8], 2[8]$ \\
\hline & & Open & $1[8], 2[8,58,59]$ \\
\hline & \multirow{2}{*}{ Gypsum } & Closed & $1[10,13,47], 2[48,60], 3[60]$, multiple $[60]$ \\
\hline & & Open & $1[10,18,47,61], 2[47,60,61], 3[58,60-62]$, multiple $[60,62]$ \\
\hline
\end{tabular}

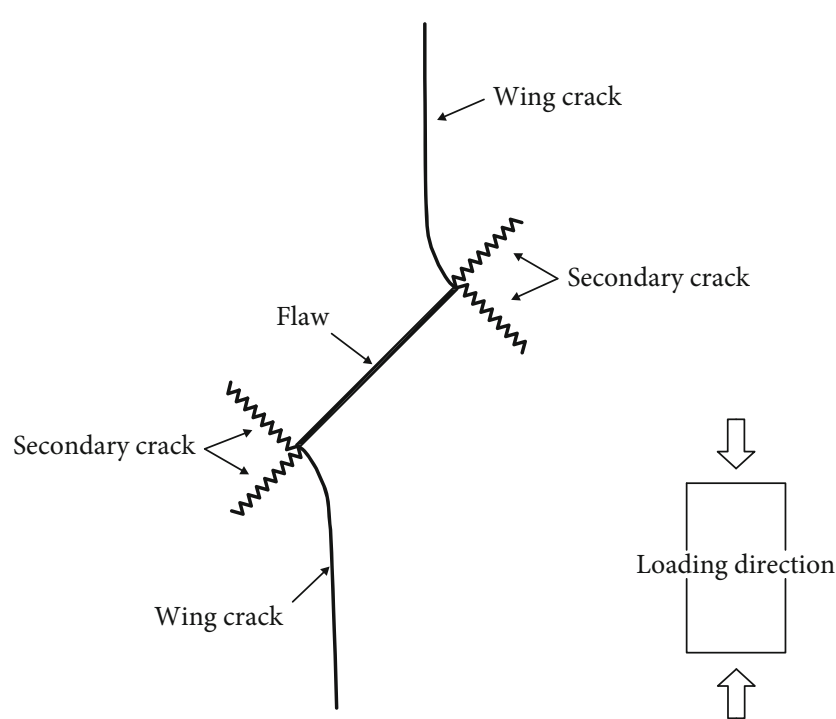

FIGURE 1: Simplified crack pattern in precracked specimens under uniaxial compression [10].

is heterogeneous, the future research in this field should focus on three-dimensional internal flaws and find more suitable materials to simulate the influence of heterogeneity on the fracture of the rock mass.

\section{Numerical Simulation Methods}

In recent years, with the deepening of mathematical and mechanical theories and the rapid development of computer technology, numerical simulation methods have been widely used in the theoretical research and engineering problem processing of geotechnical engineering [70-77]. The main numerical simulation methods for the jointed rock massrelated problem are the Finite Element Method (FEM), Finite Difference Method (FDM), Element-Free Method (EFM) and Boundary Element Method (BEM), Discrete Element Method (DEM), Numerical Manifold Method (NMM), and Discontinuous Deformation Analysis (DDA).
FEM is the widely used simulation method in the study of rock fracture mechanics $[78,79]$. The solution of the stress field at the crack tip, the calculation of the stress intensity factor, and the $J$-integral can all be solved by FEM. Bittencourt et al. [80] used a local mesh adjustment technique to simulate crack propagation of linear elastic materials in the two-dimensional finite element program. Li and Wong [81] analyzed the influence of a preexisting flaw inclination angle on the initiation position and angle of the potential cracks by FEM analysis on the stress field distribution. However, FEM has many inconveniences in simulating the rock fracture process. For example, when analyzing crack growth and some extremely large deformation problems, it needs to constantly redraw the grid, thus increasing the workload. To avoid such problems, in 1999, Belytschko [82, 83] proposed a new method to deal with the discontinuity proble$\mathrm{m}$-Extended Finite Element Method (XFEM). In XFEM, the finite element mesh and crack are independent of each other, which makes it convenient to analyze discontinuities of cracked bodies, leading to its widespread application [84-86]. Xie et al. [87] used XFEM to investigate the crack initiation and propagation in rock-like material with closed fissure under uniaxial compression. Zhuang et al. [88] compared the fracture behavior of unfilled and filled preexisting flaws by XFEM and found that they were different in crack initiation stress and angle.

FLAC $^{3 \mathrm{D}}$ is the most widely used FDM software which can solve many complex engineering problems that are difficult to be simulated by the finite element program because of its fast Lagrangian explicit finite-difference method. Fu et al. [89] imported a new modified elastic-brittle theory into FLAC $^{3 \mathrm{D}}$ to simulate the fracture development of jointed rock mass, and the results are in good agreement with the experiment. By employing FLAC ${ }^{3 \mathrm{D}}$, Guo et al. [90] perfectly captured the general features of brittle materials under compression including the fracturing process and $\mathrm{AE}$ events as well as stress-strain curves and found that peak stress and crack initiation stress are both heterogeneity dependent.

With the rapid development of computing technology, more and more scholars pay attention to DEM to simulate the crack initiation and propagation of rock materials [91]. DEM treats rock materials as a collective composed of a large 
number of tiny particles. For crack initiation and propagation, the PFC has been widely accepted by scholars, and the numerical results show great agreement with the experimental results [92-103]. Potyondy [92] introduced the basic principle of particle flow in detail and adopted the bonded particle model (BPM) to simulate the mechanical properties of rock material. Manouchehrian et al. [93] applied BPM in PFC2D to study the effect of the flaw orientation on the crack propagation mechanism in brittle materials such as rocks under various compressive loads. The numerical results show that the flaw inclination angle and confinement pressure have a strong influence on crack initiation and propagation behavior. Based on the parallel bond model, Zhang and Wong [94] investigated the crack initiation and propagation under uniaxial compressive loading and got similar results with Manouchehrian et al. [93].

Figure S3 shows a comparison of the simulation results of the three most commonly used methods for simulating rock fracture processes. The crack path can be seen clearly in XFEM, but restricted by the single selection of the cracking criteria, only wing cracks appear in the simulation results, and no other secondary cracks appear. In FLAC ${ }^{3 \mathrm{D}}$, because of the indivisibility of the mesh, there is no real crack in the simulation results, only the plastic elements can be used to represent the rock failure, and the crack shown in the figure is composed of the plastic elements. Compared with the above two methods, PFC has a great advantage in simulating rock cracking. The fracture of the bond between particles is applied to simulate the rock fracture, which is more in line with the actual situation. In addition, it can simulate the initiation and propagation of tensile cracks and shear cracks simultaneously. This makes its simulation results closest to the experimental results in many simulation methods. Therefore, DEM that is represented by PFC gradually becomes the most widely employed method to simulate rock fracture behavior.

It is worth noting that although many researchers have employed numerical methods to simulate the compression of rock specimens with initial flaws, the simulation results often differ from the real situation. The main reason is that the present simulation methods often assume that the material is completely homogeneous in the simulation and do not consider the weakening of the mechanical properties of the material caused by the expansion of cracks in the compression process, which is quite different from the actual situation. Therefore, future research on numerical simulation should focus on solving the above two problems to make the simulation results more practical.

\section{Discussion and Conclusions}

The study of the fracture and failure characteristics of jointed rock mass is of considerable significance to engineering. This review summarizes the recent achievements of investigation into the fracture behaviors of rock with initial damage in theoretical, experimental, and numerical aspects, respectively, and gives some suggestions on future researches.

Many fracture criteria have been proposed that can describe the fracture behavior of precracked specimens under compression. However, until now, there is a lack of a commonly applicable or generally accepted theory. And there are few studies on three-dimensional flaws. Therefore, the theoretical research on rock fracture in the future should focus on exploring a more reasonable two-dimensional fracture theory and strengthening the research on threedimensional crack growth.

Plenty of experimental results on rock specimens with preexisting flaws show that there are often two types of cracks in a 2D situation: wing crack and secondary crack. And the coalescence types of cracks in the specimen with multiple flaws are dependent on geometry of flaws. Moreover, many differences between three-dimensional flaws and twodimensional flaws in rock mass have been found, which indicates that an experimental test of three-dimensional flaws is extremely necessary for the study of actual rock mass flaws. Therefore, future research in this field should focus on three-dimensional internal flaws and find more suitable materials to simulate the influence of heterogeneity on the fracture of the rock mass.

Numerical simulation is a beneficial supplement and verification of the experimental analysis and theoretical research. Different kinds of methods have been indicated that could substantially simulate the fracture behavior of specimens with preexisting flaws. DEM, which shows a substantial advantage of crack initiation and propagation, has been gradually accepted by more scholars. Future research on numerical simulation should focus on considering the heterogeneity of the material and the weakening of the mechanical properties of the material in the process of crack growth to make the simulation results more practical.

\section{Conflicts of Interest}

The authors declare that the research was conducted in the absence of any commercial or financial relationships that could be construed as a potential conflict of interest.

\section{Authors' Contributions}

Hui Zhang provides the idea of the article and writes the text. Panpan Guo offers detailed guidance on the method of the article. Yixian Wang mainly collects the theoretical achievements of this research area. Yanlin Zhao, Lin Hang, Yan Liu, and Yahui Shao revise the final version of the paper.

\section{Acknowledgments}

This work was supported by the National Natural Science Foundation of China (Nos. 51774107, 51774322, 51774131, and 51874112), the Fundamental Research Funds for the Central Universities of China (JD2020JGPY0011), the State Key Laboratory of Explosion Science and Technology (Beijing Institute of Technology) (No. KFJJ19-02M), and the Hunan Provincial Natural Science Foundation of China (No. 2018JJ2500). 


\section{Supplementary Materials}

Figure S1: some experimental results of rock specimens containing more than one flaw: (a) two flaws [8]; (b) three flaws [43]; (c) multiple flaws [51]. Figure S2: petal cracks in a specimen containing a 3D surface flaw observed by Wong et al. [58]. Figure S3: different simulation results of cracks in rock specimens: (a) XFEM [86]; (b) FLAC ${ }^{3 \mathrm{D}}$ [89]; (c) PFC [51]. (Supplementary Materials)

\section{References}

[1] D. W. Yin, S. J. Chen, X. Q. Liu, and H. F. Ma, "Effect of joint angle in coal on failure mechanical behaviour of roof rockcoal combined body," Quarterly Journal of Engineering Geology and Hydrogeology, vol. 51, no. 2, pp. 202-209, 2018.

[2] B. Li, N. Xu, F. Dai, G. Zhang, and P. Xiao, "Dynamic analysis of rock mass deformation in large underground caverns considering microseismic data," International Journal of Rock Mechanics and Mining Sciences, vol. 122, article 114078, 2019.

[3] S. Q. Yang and H. W. Jing, "Strength failure and crack coalescence behavior of brittle sandstone samples containing a single fissure under uniaxial compression," International Journal of Fracture, vol. 168, no. 2, pp. 227-250, 2011.

[4] P. Baud, T. Reuschlé, and P. Charlez, "An improved wing crack model for the deformation and failure of rock in compression," International journal of rock mechanics and mining sciences \& geomechanics abstracts, vol. 33, no. 5, pp. 539-542, 1996.

[5] A. Li, F. Dai, N. W. Xu, G. K. Gu, and Z. H. Hu, "Analysis of a complex flexural toppling failure of large underground caverns in layered rock masses," Rock Mechanics and Rock Engineering, vol. 52, no. 9, pp. 3157-3181, 2019.

[6] C. A. Tang, Z. Z. Liang, Y. B. Zhang, and T. Xu, "Threedimensional material failure process analysis," Key Engineering Materials, vol. 297-300, pp. 1196-1201, 2005.

[7] A. Li, Y. Liu, F. Dai, K. Liu, and M. D. Wei, "Continuum analysis of the structurally controlled displacements for largescale underground caverns in bedded rock masses," Tunnelling and Underground Space Technology, vol. 97, article 103288, 2020.

[8] H. Lee and S. Jeon, "An experimental and numerical study of fracture coalescence in pre-cracked specimens under uniaxial compression," International Journal of Solids and Structures, vol. 48, no. 6, pp. 979-999, 2011.

[9] R. H. C. Wong and K. T. Chau, "Crack coalescence in a rocklike material containing two cracks," International Journal of Rock Mechanics and Mining Sciences, vol. 35, no. 2, pp. 147164, 1998.

[10] A. Bobet, "The initiation of secondary cracks in compression," Engineering Fracture Mechanics, vol. 66, no. 2, pp. 187-219, 2000.

[11] P. Cao, T. Liu, C. Pu, and H. Lin, "Crack propagation and coalescence of brittle rock-like specimens with pre-existing cracks in compression," Engineering Geology, vol. 187, pp. 113-121, 2015.

[12] P. Yin, R. H. C. Wong, and K. T. Chau, "Coalescence of two parallel pre-existing surface cracks in granite," International Journal of Rock Mechanics and Mining Sciences, vol. 68, pp. 66-84, 2014.
[13] L. N. Y. Wong and H. H. Einstein, "Systematic evaluation of cracking behavior in specimens containing single flaws under uniaxial compression," International Journal of Rock Mechanics and Mining Sciences, vol. 46, no. 2, pp. 239-249, 2009.

[14] M. D. Wei, F. Dai, N. W. Xu, T. Zhao, and Y. Liu, "An experimental and theoretical assessment of semi-circular bend specimens with chevron and straight-through notches for mode I fracture toughness testing of rocks," International Journal of Rock Mechanics and Mining Sciences, vol. 99, pp. 28-38, 2017.

[15] P. Feng, F. Dai, Y. Liu, N. W. Xu, and P. X. Fan, "Effects of coupled static and dynamic strain rates on the mechanical behaviors of rock-like specimens containing preexisting fissures under uniaxial compression," Canadian Geotechnical Journal, vol. 55, no. 5, pp. 640-652, 2018.

[16] Y. Liu, F. Dai, L. Dong, N. W. Xu, and P. Feng, "Experimental investigation on the fatigue mechanical properties of intermittently jointed rock models under cyclic uniaxial compression with different loading parameters," Rock Mechanics and Rock Engineering, vol. 51, no. 1, pp. 47-68, 2018.

[17] Y. Liu and F. Dai, "A damage constitutive model for intermittent jointed rocks under cyclic uniaxial compression," International Journal of Rock Mechanics and Mining Sciences, vol. 103, pp. 289-301, 2018.

[18] F. Erdogan and G. C. Sih, "On the crack extension in plates under plane loading and transverse shear," Journal of Basic Engineering, vol. 85, no. 4, pp. 519-525, 1963.

[19] M. D. Wei, F. Dai, J. W. Zhou, Y. Liu, and J. Luo, "A further improved maximum tangential stress criterion for assessing mode I fracture of rocks considering non-singular stress terms of the Williams expansion," Rock Mechanics and Rock Engineering, vol. 51, no. 11, pp. 3471-3488, 2018.

[20] K. Palaniswamy and W. G. Knauss, "On the problem of crack extension in brittle solids under general loading," Mechanics Today, vol. 4, pp. 87-148, 1978.

[21] K. Palaniswamy, "Crack propagation under general in-plane loading," California Institute of Technology, [Ph.D. thesis], Caltech THESIS, 1972.

[22] M. I. Husseini, D. B. Jovanovich, M. J. Randall, and L. B. Freund, "The fracture energy of earthquakes," Geophysical Journal of the Royal Astronomical Society, vol. 43, no. 2, pp. 367-385, 1975.

[23] G. C. Sih, "Strain-energy-density factor applied to mixed mode crack problems," International Journal of Fracture, vol. 10, no. 3, pp. 305-321, 1974.

[24] M. D. Wei, F. Dai, N. W. Xu, Y. Liu, and T. Zhao, "Fracture prediction of rocks under mode I and mode II loading using the generalized maximum tangential strain criterion," Engineering Fracture Mechanics, vol. 186, pp. 21-38, 2017.

[25] M. R. M. Aliha and M. R. Ayatollahi, "Analysis of fracture initiation angle in some cracked ceramics using the generalized maximum tangential stress criterion," International Journal of Solids and Structures, vol. 49, no. 13, pp. 1877-1883, 2012.

[26] A. Oral, J. Lambros, and G. Anlas, "Crack initiation in functionally graded materials under mixed mode loading: experiments and simulations," Journal of Applied Mechanics, vol. 75, no. 5, article 051110, 2008.

[27] P. Cao, W. Youdao, W. Yixian, Y. Haiping, and Y. Bingxiang, "Study on nonlinear damage creep constitutive model for 
high-stress soft rock," Environmental Earth Science, vol. 75, no. 10, 2016

[28] S. B. Tang, C. Y. Bao, and H. Y. Liu, "Brittle fracture of rock under combined tensile and compressive loading," Canadian Geotechnical Journal, vol. 54, no. 1, pp. 88-101, 2017.

[29] X. P. Zhou, "Triaxial compressive behavior of rock with mesoscopic heterogenous behavior: strain energy density factor approach," Theoretical and Applied Fracture Mechanics, vol. 45, no. 1, pp. 46-63, 2006.

[30] P. Lazzarin, F. Berto, F. Gomez, and M. Zappalorto, "Some advantages derived from the use of the strain energy density over a control volume in fatigue strength assessments of welded joints," International Journal of Fatigue, vol. 30, no. 8, pp. 1345-1357, 2008.

[31] X. P. Zhou, H. Q. Yang, and Y. X. Zhang, "Rate dependent critical strain energy density factor of Huanglong limestone," Theoretical and Applied Fracture Mechanics, vol. 51, no. 1, pp. 57-61, 2009.

[32] K. Hayashi and S. Nemat-Nasser, "Energy release rate and crack kinking," International Journal of Solids and Structures, vol. 17, no. 1, pp. 107-114, 1981.

[33] C. G. Hwang, P. A. Wawrzynek, A. K. Tayebi, and A. R. Ingraffea, "On the virtual crack extension method for calculation of the rates of energy release rate," Engineering Fracture Mechanics, vol. 59, no. 4, pp. 521-542, 1998.

[34] Y. G. Matvienko, "Maximum average tangential stress criterion for prediction of the crack path," International Journal of Fracture, vol. 176, no. 1, pp. 113-118, 2012.

[35] S. M. A. Khan and M. K. Khraisheh, "A new criterion for mixed mode fracture initiation based on the crack tip plastic core region," International Journal of Plasticity, vol. 20, no. 1, pp. 55-84, 2004.

[36] B. Shen and O. Stephansson, "Modification of the G-criterion for crack propagation subjected to compression," Engineering Fracture Mechanics, vol. 47, no. 2, pp. 177-189, 1994.

[37] B. Shen, "The mechanism of fracture coalescence in compression-experimental study and numerical simulation," Engineering Fracture Mechanics, vol. 51, no. 1, pp. 73-85, 1995.

[38] Q. Rao, Z. Sun, O. Stephansson, C. Li, and B. Stillborg, "Shear fracture (mode II) of brittle rock," International Journal of Rock Mechanics and Mining Sciences, vol. 40, no. 3, pp. 355-375, 2003.

[39] Z. Q. Sun, "Is crack branching under shear loading caused by shear fracture? - - A critical review on maximum circumferential stress theory," Transactions of Nonferrous Metals Society of China, vol. 11, no. 2, pp. 287-292, 2001.

[40] J. Chang, J. Q. Xu, and Y. Mutoh, "A general mixed-mode brittle fracture criterion for cracked materials," Engineering Fracture Mechanics, vol. 73, no. 9, pp. 1249-1263, 2006.

[41] M. D. Wei, F. Dai, N. W. Xu, Y. Liu, and T. Zhao, "A novel chevron notched short rod bend method for measuring the mode I fracture toughness of rocks," Engineering Fracture Mechanics, vol. 190, pp. 1-15, 2018.

[42] S. P. Morgan, C. A. Johnson, and H. H. Einstein, "Cracking processes in Barre granite: fracture process zones and crack coalescence," International Journal of Fracture, vol. 180, no. 2, pp. 177-204, 2013.

[43] X. P. Zhou, G. Q. Li, and H. C. Ma, "Real-time experiment investigations on the coupled thermomechanical and cracking behaviors in granite containing three pre-existing fis- sures," Engineering Fracture Mechanics, vol. 224, article 106797, 2020.

[44] D. Huang, D. Gu, C. Yang, R. Q. Huang, and G. Y. Fu, "Investigation on mechanical behaviors of sandstone with two preexisting flaws under triaxial compression," Rock Mechanics and Rock Engineering, vol. 49, no. 2, pp. 375-399, 2016.

[45] S. Q. Yang, "Crack coalescence behavior of brittle sandstone samples containing two coplanar fissures in the process of deformation failure," Engineering Fracture Mechanics, vol. 78, no. 17, pp. 3059-3081, 2011.

[46] S. Q. Yang, D. S. Yang, H. W. Jing, Y. H. Li, and S. Y. Wang, "An experimental study of the fracture coalescence behaviour of brittle sandstone specimens containing three fissures," Rock Mechanics and Rock Engineering, vol. 45, no. 4, pp. 563-582, 2012.

[47] Z. Brooks, F. J. Ulm, and H. H. Einstein, "Environmental scanning electron microscopy (ESEM) and nanoindentation investigation of the crack tip process zone in marble," Acta Geotechnica, vol. 8, no. 3, pp. 223-245, 2013.

[48] A. Bobet and H. H. Einstein, "Fracture coalescence in rocktype materials under uniaxial and biaxial compression," International Journal of Rock Mechanics and Mining Sciences, vol. 35, no. 7, pp. 863-888, 1998.

[49] Y. P. Li, L. Z. Chen, and Y. H. Wang, "Experimental research on pre-cracked marble under compression," International Journal of Solids and Structures, vol. 42, no. 9-10, pp. 25052516, 2005.

[50] R. H. Cao, P. Cao, H. Lin, G. W. Ma, C. Y. Zhang, and C. Jiang, "Failure characteristics of jointed rock-like material containing multi-joints under a compressive-shear test: experimental and numerical analyses," Archives of Civil and Mechanical Engineering, vol. 18, no. 3, pp. 784-798, 2018.

[51] R. H. Cao, P. Cao, X. Fan, X. G. Xiong, and H. Lin, “An experimental and numerical study on mechanical behavior of ubiquitous-joint brittle rock-like specimens under uniaxial compression," Rock Mechanics and Rock Engineering, vol. 49, no. 11, pp. 4319-4338, 2016.

[52] J. Jin, P. Cao, Y. Chen, C. Z. Pu, D. W. Mao, and X. Fan, "Influence of single flaw on the failure process and energy mechanics of rock-like material," Computers and Geotechnics, vol. 86, pp. 150-162, 2017.

[53] H. Lin, H. T. Yang, Y. X. Wang, Y. L. Zhao, and R. H. Cao, "Determination of the stress field and crack initiation angle of an open flaw tip under uniaxial compression," Theoretical and Applied Fracture Mechanics, vol. 104, article 102358, 2019.

[54] Y. Zhao, L. Zhang, W. Wang, C. Pu, W. Wan, and J. Tang, "Cracking and stress-strain behavior of rock-like material containing two flaws under uniaxial compression," Rock Mechanics and Rock Engineering, vol. 49, no. 7, pp. 26652687, 2016.

[55] H. Haeri, K. Shahriar, M. F. Marji, and P. Moarefvand, "Cracks coalescence mechanism and cracks propagation paths in rock-like specimens containing pre-existing random cracks under compression," Journal of Central South University, vol. 21, no. 6, pp. 2404-2414, 2014.

[56] M. Prudencio and M. van Sint Jan, "Strength and failure modes of rock mass models with non-persistent joints," International Journal of Rock Mechanics and Mining Sciences, vol. 44, no. 6, pp. 890-902, 2007.

[57] R. H. Cao, P. Cao, H. Lin, C. Z. Pu, and K. Ou, "Mechanical behavior of brittle rock-like specimens with pre-existing 
fissures under uniaxial loading: experimental studies and particle mechanics approach," Rock Mechanics and Rock Engineering, vol. 49, no. 3, pp. 763-783, 2016.

[58] R. H. C. Wong, C. M. Law, K. T. Chau, and W. S. Zhu, "Crack propagation from 3-d surface fractures in PMMA and marble specimens under uniaxial compression," International Journal of Rock Mechanics and Mining Sciences, vol. 41, no. 3, Supplement 1, pp. 37-42, 2004.

[59] M. Huang and R. H. C. Wong, "Experimental study on propagation and coalescence mechanisms of 3D surface cracks," Chinese Journal of Rock Mechanics and Engineering, vol. 26, no. 9, pp. 1794-1799, 2007.

[60] C. H. Park and A. Bobet, "Crack coalescence in specimens with open and closed flaws: a comparison," International Journal of Rock Mechanics and Mining Sciences, vol. 46, no. 5, pp. 819-829, 2009.

[61] J. Xu and Z. Li, "Crack propagation and coalescence of steppath failure in rocks," Rock Mechanics and Rock Engineering, vol. 52, no. 4, pp. 965-979, 2019.

[62] M. Sagong and A. Bobet, "Coalescence of multiple flaws in a rock-model material in uniaxial compression," International Journal of Rock Mechanics and Mining Sciences, vol. 39, no. 2, pp. 229-241, 2002.

[63] H. Chen, X. Fan, H. P. Lai, Y. L. Xie, and Z. M. He, "Experimental and numerical study of granite blocks containing two side flaws and a tunnel-shaped opening," Theoretical and Applied Fracture Mechanics, vol. 104, article 102394, 2019.

[64] Y. Zhao, Y. Wang, W. Wang, W. Wan, and J. Tang, "Modeling of non-linear rheological behavior of hard rock using triaxial rheological experiment," International Journal of Rock Mechanics and Mining Sciences, vol. 93, pp. 66-75, 2017.

[65] B. Shen, O. Stephansson, H. H. Einstein, and B. Ghahreman, "Coalescence of fractures under shear stresses in experiments," Journal of Geophysical Research, vol. 100, no. B4, pp. 5975-5990, 1995.

[66] A. V. Dyskin, R. J. Jewell, H. Joer, E. Sahouryeh, and K. B. Ustinov, "Experiments on 3-D crack growth in uniaxial compression," International Journal of Fracture, vol. 65, no. 4, pp. 77-83, 1994.

[67] A. V. Dyskin, L. N. Germanovich, and K. B. Ustinov, "A 3-D model of wing crack growth and interaction," Engineering Fracture Mechanics, vol. 63, no. 1, pp. 81-110, 1999.

[68] L. N. Germanovich, R. L. Salganik, A. V. Dyskin, and K. K. Lee, "Mechanisms of brittle fracture of rock with preexisting cracks in compression," Pure and Applied Geophysics, vol. 143, no. 1-3, pp. 117-149, 1994.

[69] Z. D. Zhu, H. X. Lin, and Y. L. Sun, "An experimental study of internal 3D crack propagation and coalescence in transparent rock," Rock and Soil Mechanics, vol. 37, no. 928, pp. 913-921, 2016.

[70] Y. Xu and P. Guo, "Disturbance evolution behavior of loess soil under triaxial compression," Advances in Civil Engineering, vol. 2020, Article ID 4160898, 14 pages, 2020.

[71] X. P. Zhou, J. Bi, and Q. H. Qian, "Numerical simulation of crack growth and coalescence in rock-like materials containing multiple pre-existing flaws," Rock Mechanics and Rock Engineering, vol. 48, no. 3, pp. 1097-1114, 2015.

[72] P. Guo, X. Gong, and Y. Wang, "Displacement and force analyses of braced structure of deep excavation considering unsymmetrical surcharge effect," Computers and Geotechnics, vol. 113, article 103102, 2019.
[73] H. Zheng and D. Xu, "New strategies for some issues of numerical manifold method in simulation of crack propagation," International Journal for Numerical Methods in Engineering, vol. 97, no. 13, pp. 986-1010, 2014.

[74] Y. L. Zhao, S. L. Luo, Y. X. Wang, W. J. Wang, L. Y. Zhang, and W. Wan, "Numerical analysis of karst water inrush and a criterion for establishing the width of water-resistant rock pillars," Mine Water and the Environment, vol. 36, no. 4, pp. 508-519, 2017.

[75] A. Golshani, M. Oda, Y. Okui, T. Takemura, and E. Munkhtogoo, "Numerical simulation of the excavation damaged zone around an opening in brittle rock," International Journal of Rock Mechanics and Mining Sciences, vol. 44, no. 6, pp. 835-845, 2007.

[76] Y. X. Wang, P. P. Guo, H. Lin et al., "Numerical analysis of fiber-reinforced soils based on the equivalent additional stress concept," International Journal of Geomechanics, vol. 19, no. 11, article 04019122, 2019.

[77] H. Lin, P. Cao, and Y. Wang, "Numerical simulation of a layered rock under triaxial compression," International Journal of Rock Mechanics and Mining Sciences, vol. 60, pp. 12-18, 2013.

[78] M. D. Wei, F. Dai, N. W. Xu, T. Zhao, and K. W. Xia, "Experimental and numerical study on the fracture process zone and fracture toughness determination for ISRM-suggested semicircular bend rock specimen," Engineering Fracture Mechanics, vol. 154, pp. 43-56, 2016.

[79] Y. X. Wang, H. Zhang, H. Lin, Y. L. Zhao, X. Li, and Y. Liu, "Mechanical behavior and failure analysis of fracture-filled gneissic granite," Theoretical and Applied Fracture Mechanics, vol. 108, article 102647, p. 102674, 2020.

[80] T. N. Bittencourt, P. A. Wawrzynek, A. R. Ingraffea, and J. L. Sousa, "Quasi-automatic simulation of crack propagation for 2D LEFM problems," Engineering Fracture Mechanics, vol. 55, no. 2, pp. 321-334, 1996.

[81] H. Li and L. N. Y. Wong, "Influence of flaw inclination angle and loading condition on crack initiation and propagation," International Journal of Solids and Structures, vol. 49, no. 18, pp. 2482-2499, 2012.

[82] T. Belytschko and T. Black, "Elastic crack growth in finite elements with minimal remeshing," International Journal for Numerical Methods in Engineering, vol. 45, no. 5, pp. 601620, 1999.

[83] M. Nicolas, J. Dolbow, and T. Belytschko, "A finite element method for crack growth without remeshing," International Journal for Numerical Methods in Engineering, vol. 46, pp. 131-150, 1999.

[84] T. T. Yu, "The extended finite element method (XFEM) for discontinuous rock masses," Engineering Computations, vol. 28, no. 3, pp. 340-369, 2011.

[85] Y. L. Zhang and X. T. Feng, "Extended finite element simulation of crack propagation in fractured rock masses," Materials Research Innovations, vol. 15, supplement 1, pp. s594s596, 2011.

[86] Y. X. Wang, H. Zhang, H. Lin, Y. L. Zhao, and Y. Liu, "Fracture behaviour of central-flawed rock plate under uniaxial compression," Theoretical and Applied Fracture Mechanics, vol. 106, article 102503, 2020.

[87] Y. Xie, P. Cao, J. Liu, and L. Dong, "Influence of crack surface friction on crack initiation and propagation: a numerical 
investigation based on extended finite element method," Computers and Geotechnics, vol. 74, pp. 1-14, 2016.

[88] X. Zhuang, J. Chun, and H. Zhu, “A comparative study on unfilled and filled crack propagation for rock-like brittle material," Theoretical and Applied Fracture Mechanics, vol. 72, pp. 110-120, 2014.

[89] J. W. Fu, X. Z. Zhang, W. S. Zhu, K. Chen, and J. F. Guan, "Simulating progressive failure in brittle jointed rock masses using a modified elastic-brittle model and the application," Engineering Fracture Mechanics, vol. 178, pp. 212-230, 2017.

[90] S. Guo, S. Qi, Y. Zou, and B. Zheng, "Numerical studies on the failure process of heterogeneous brittle rocks or rocklike materials under uniaxial compression," Materials, vol. 10, no. 4, 2017.

[91] Y. Xu and F. Dai, "Dynamic response and failure mechanism of brittle rocks under combined compression-shear loading experiments," Rock Mechanics and Rock Engineering, vol. 51, no. 3, pp. 747-764, 2018.

[92] D. O. Potyondy and P. A. Cundall, "A bonded-particle model for rock," International Journal of Rock Mechanics and Mining Sciences, vol. 41, no. 8, pp. 1329-1364, 2004.

[93] A. Manouchehrian, M. Sharifzadeh, M. F. Marji, and J. Gholamnejad, "A bonded particle model for analysis of the flaw orientation effect on crack propagation mechanism in brittle materials under compression," Archives of civil and mechanical engineering, vol. 14, no. 1, pp. 40-52, 2014.

[94] X. P. Zhang and L. N. Y. Wong, "Cracking processes in rocklike material containing a single flaw under uniaxial compression: a numerical study based on parallel bonded-particle model approach," Rock Mechanics and Rock Engineering, vol. 45, no. 5, pp. 711-737, 2012.

[95] X. Fan, P. H. S. W. Kulatilake, and X. Chen, "Mechanical behavior of rock-like jointed blocks with multi-nonpersistent joints under uniaxial loading: a particle mechanics approach," Engineering Geology, vol. 190, pp. 17-32, 2015.

[96] C. P. Lu, L. M. Dou, X. R. Wu, and Y. S. Xie, "Case study of blast-induced shock wave propagation in coal and rock," International Journal of Rock Mechanics and Mining Sciences, vol. 47, no. 6, pp. 1046-1054, 2010.

[97] C. P. Lu, Y. Liu, G. J. Liu, and T. B. Zhao, "Stress evolution caused by hard roof fracturing and associated multiparameter precursors," Tunnelling and Underground Space Technology, vol. 84, pp. 295-305, 2019.

[98] C. P. Lu, G. J. Liu, Y. Liu, and H. Zhang, "Mechanisms of rockburst triggered by slip and fracture of coal-parting-coal structure discontinuities," Rock Mechanics and Rock Engineering, vol. 52, no. 9, pp. 3279-3292, 2019.

[99] L. Dong, X. Tong, X. Li, J. Zhou, S. Wang, and B. Liu, "Some developments and new insights of environmental problems and deep mining strategy for cleaner production in mines," Journal of Cleaner Production, vol. 210, pp. 1562-1578, 2019.

[100] L. Dong, J. Wang, X. Li, and K. Peng, "Dynamic stability analysis of rockmass: a review," Advances in Civil Engineering, vol. 2018, Article ID 4270187, 22 pages, 2018.

[101] L. Dong, W. Zou, D. Sun, X. Tong, X. Li, and W. Shu, "Some developments and new insights for microseismic/acoustic emission source localization," Shock and Vibration, vol. 2019, Article ID 9732606, 15 pages, 2019.
[102] H. Lin, S. J. Xie, R. Yong, Y. F. Chen, and S. du, “An empirical statistical constitutive relationship for rock joint shearing considering scale effect," Comptes Rendus Mécanique, vol. 347, no. 8, pp. 561-575, 2019.

[103] Y. Qian, P. Guo, Y. Wang, Y. Zhao, H. Lin, and Y. Liu, "Advances in laboratory-scale hydraulic fracturing experiments," Advances in Civil Engineering, vol. 2020, Article ID 1386581, 18 pages, 2020. 